
Kidney
Blood Pressure Research

\begin{tabular}{|c|c|}
\hline \multicolumn{2}{|c|}{ Kidney Blood Press Res 2018;43:479-489 } \\
\hline $\begin{array}{l}\text { DOI: 10.1159/000488694 } \\
\text { Published onlIne: April6, } 2018\end{array}$ & $\begin{array}{l}\text { (C) } 2018 \text { The Author(s) } \\
\text { Published by S. Karger AG, Basel } \\
\text { www.karger.com/kbr }\end{array}$ \\
\hline
\end{tabular}

This article is licensed under the Creative Commons Attribution-NonCommercial-NoDerivatives 4.0 InternaThis article is licensed under the Creative Commons Attribution-NonCommercial-NoDerivatives 4.0 Interna-
tional License (CC BY-NC-ND) (http:/www.karger.com/Services/OpenAccessLicense). Usage and distribution for commercial purposes as well as any distribution of modified material requires written permission.

\title{
Combination of Mean Platelet Volume/ Platelet Count Ratio and the APACHE II Score Better Predicts the Short-Term Outcome in Patients with Acute Kidney Injury Receiving Continuous Renal Replacement Therapy
}

\author{
Junhui Lia Yingchuan Lib Xiaohua Shenga Feng Wang ${ }^{a} \quad$ Dongsheng Cheng ${ }^{a}$ \\ Guihua Jian ${ }^{\mathrm{a}}$ Yongguang Lic $^{\mathrm{c}}$ Liang Feng $^{\mathrm{d}}$ Niansong Wang ${ }^{\mathrm{a}}$
}

aDepartment of Nephrology, Shanghai Jiao Tong University affiliated Sixth People's Hospital, Shanghai, bDepartment of Critical Care Medicine, Shanghai Jiao Tong University affiliated Sixth People's Hospital, Shanghai, 'Department of Cardiology, Shanghai Jiao Tong University affiliated Sixth People's Hospital, Shanghai, 'Key Laboratory of New Drug Delivery System of Chinese Meteria Medica, Jiangsu Provincial Academy of Chinese Medicine, Nanjing, China

\section{Key Words}

Mean platelet volume - Platelet Count • Acute kidney injury • Continuous renal replacement therapy • Mortality

\footnotetext{
Abstract

Background/Aims: Both the Acute physiology and Chronic Health Evaluation (APACHE II) score and mean platelet volume/platelet count Ratio (MPR) can independently predict adverse outcomes in critically ill patients. This study was aimed to investigate whether the combination of them could have a better performance in predicting prognosis of patients with acute kidney injury (AKI) who received continuous renal replacement therapy (CRRT). Methods: Two hundred twenty-three patients with AKI who underwent CRRT between January 2009 and December 2014 in a Chinese university hospital were enrolled. They were divided into survivals group and non-survivals group based on the situation at discharge. Receiver Operating Characteristic (ROC) curve was used for MPR and APACHE II score, and to determine the optimal cut-off value of MPR for in-hospital mortality. Factors associated with mortality were identified by univariate and multivariate logistic regression analysis. Results: The mean age of the patients was 61.4 years, and the overall in-hospital mortality was $48.4 \%$. Acute cardiorenal syndrome

J. Li and Y. Li contributed equally to this work. 


\section{Kidney Blood Pressure Research}

Kidney Blood Press Res 2018;43:479-489
\begin{tabular}{l|l} 
DOI: 10.1159/000488694 & $\begin{array}{l}\text { ( ) 2018 The Author(s). Published by S. Karger AG, Basel } \\
\text { www.karger.com/kbr }\end{array}$ \\
Published online: April 6, 2018 &
\end{tabular}

Li et al.: Mean Platelet Volume/Platelet Count Ratio and Acute Kidney Injury

(ACRS) was the most common cause of AKI. The optimal cut-off value of MPR for mortality was 0.099 with an area under the ROC curve (AUC) of 0.636. The AUC increased to 0.851 with the addition of the APACHE II score. The mortality of patients with of MPR $>0.099$ was $56.4 \%$, which was significantly higher than that of the control group with of $\leq 0.099(39.6 \%$, $\mathrm{P}=0.012)$. Logistic regression analysis showed that average number of organ failure $(O R=$ $2.372)$, APACHE II score $(O R=1.187)$, age $(O R=1.028)$ and vasopressors administration (OR $=38.130$ ) were significantly associated with poor prognosis. Conclusion: Severity of illness was significantly associated with prognosis of patients with AKI. The combination of MPR and APACHE II score may be helpful in predicting the short-term outcome of AKI.

(C) 2018 The Author(s)

Published by S. Karger AG, Basel

\section{Introduction}

Acute kidney injury (AKI) is a common medical condition, especially in those critically ill patients, such as major surgery, sepsis, trauma, cardiogenic shock, low blood volume and use of nephrotoxic drugs [1]. Despite continuing advances in the treatment of kidney diseases, AKI-related morbidity and mortality remain high. It is reported that AKI in the intensive care setting is associated with mortality of 40-60\% [2]. The incidence of AKI in general hospitalized patients varies from $2.0 \%$ to $20 \%$, while it is as high as $22-67 \%$ in the ICU [3-5]. A nationwide, cross-sectional survey [6] investigated 374, 286 adult patients from 44 hospitals in China. The results showed that the detection rate of AKI was $2.03 \%$. Thus, it is estimated that 1.4 to 2.9 million people with AKI were admitted to hospital in 2013. The Centers for Disease Control and Prevention (CDC) data [7] demonstrated that the incidence of AKI increased by at least 20 times between 1980 and 2005. It was also found that the risk of developing AKI in patients with chronic kidney disease (CKD) was 7 times higher than that of non-CKD patients. Meantime, recent studies suggested that patients who survived an episode of AKI had the risk of developing CKD, progression of pre-existing CKD, end-stage kidney disease (ESRD), and death [8-9].

The development of AKI is the consequence between the acute insult and subsequent activation of inflammation and coagulation. Platelets play an important role in the processes of coagulation and inflammatory, and it has been shown that platelet activation exacerbates renal injury [10]. Recently, Jansen and colleagues found during renal ischemia reperfusion injury, necrotic cell-derived DNA led to platelet activation, platelet-granulocyte interaction, and subsequent neutrophil extracellular trap formation, leading to renal inflammation and further increase in tissue injury [11]. P-selectin (CD62P) is an adhesion molecule expressed on the activated endothelium and platelets, involves in the initial attachment of leukocytes to inflamed vascular endothelium [12]. P-selectin of platelet surface is considered to be the "gold standard" marker of platelet activation [13]. However, it can't be widely used in the clinical practice due to the high detection cost and strict laboratory requirements. The MPV is calculated by automated blood analyzers, and is thought to be a marker of platelet activation in recent years [14-15]. Elevated MPV is also considered as a novel prognostic indicator in critically ill patients [16-19]. Moreover, some studies demonstrated an inverse relationship between MPV and platelet counts in critically ill patients. Emerging evidences suggested combination of platelet count and mean platelet volume may be more clinically significant than platelet count or MPV alone [20-22]. To the best of our knowledge, however, little is known about the association between MPR and prognosis in AKI.

Continuous renal replacement therapy (CRRT) is a major treatment for severe AKI, however, most of the current studies are focused on the ICU, the data of general hospitalized patients is rare. Therefore, we retrospectively analyzed the etiology, prognosis and risk factors of severe AKI patients who underwent CRRT in our whole hospital for 6 years. In addition, we investigated whether the increase in MPR or the combination of MPR and APACHE II score has prognostic value in these patients. 


\section{Kidney Blood Pressure Research}

\begin{tabular}{l} 
Kidney Blood Press Res 2018;43:479-489 \\
\begin{tabular}{l|l}
\hline DOI: 10.1159/000488694 & (c) 2018 The Author(s). Published by S. Karger AG, Basel \\
Published onlIne: Apri 6, 2018 & ww.karger.com/kbr
\end{tabular} \\
\hline
\end{tabular}

Li et al.: Mean Platelet Volume/Platelet Count Ratio and Acute Kidney Injury

\section{Materials and Methods}

\section{Study design and patients}

We conducted a retrospective single-center study in a 1, 800-bed university hospital in China. All consecutive patients with AKI who underwent CRRT between January 2009 and December 2014 were screened. This study was approved by the hospital ethics committee in accordance with medical ethics standards. Informed consents were signed by all enrolled patients. AKI diagnosis was based on serum creatinine and urine output value, according to the Kidney Disease: Improving Global Outcomes (KDIGO) clinical practice guidelines [23]. The inclusion criteria were (1) patients with AKI who underwent CRRT; (2) aged $\geq 14$ years; (3) length of hospital stay $\geq 48 \mathrm{~h}$; and (4) complete record. The exclusion criteria were as follows: aged $<14$ years, ESRD, less than 48 hours of hospital stay, missing serum creatinine value within 48 hours after admission, incomplete data. Patients were classified into survivors and non-survivors group based on the outcome at the time of discharge. Patients were also divided into MPR $\leq 0.099$ and MPR $>0.099$ group based on the optimal cut-off value of MPR.

\section{Continuous renal replacement therapy}

The criteria for initiation of CRRT for AKI were at the discretion of the nephrologist. CRRT was performed using the Aquarius bedside haemofiltration machine with an HF1200 hemofilter through a double-lumen 16G catheter inserted into the internal jugular or femoral vein. The model of CRRT was continuous veno-venous hemofiltration (CVVH) or continuous veno-venous hemodiafiltration (CVVHDF). The blood flow rate was at $150-250 \mathrm{ml} / \mathrm{min}$ with an effluent rate of $4000 \mathrm{ml} / \mathrm{h}$. No protocol was used to make the decision to cease CRRT treatment. In general, the duration of treatment was taken $24 \mathrm{~h}$ continuous or 5-10h daily, according to patient's condition. Low molecular weight heparins, unfractionated heparin or argatroban anticoagulant were used to maintain circuit patency. Heparin-free anticoagulant was used in the patients with a high risk of bleeding tendency, and the circuit was regularly rinsed with normal saline. Besides CRRT, all patients were treated with conventional treatment, such as fluid resuscitation, vasopressors, anti-infectives, respiratory support, nutritional support and vital signs monitoring.

\section{Data collection}

Data was obtained from our hospital electronic medical record system, a computerized system used for daily patient documentation, and verified with the written records of each patient. General information on demographic, clinical data and CRRT associated data were collected. Clinical data comprised admission diagnoses, admitted to the department, comorbidities (diabetes mellitus, hypertension), severity of illness, hematological and biochemical parameters, drug administration and mechanical ventilation use. The ICU in this study refers to department of intensive care unit, and Surgical intensive care unit (SICU), emergency intensive care unit (EICU), coronary heart disease intensive care unit (CCU), respiratory intensive care unit (RICU), Cardiothoracic Surgery intensive care unit(CSICU) neurosurgical intensive care unit (NSICU), neurological intensive care unit (NSICU), etc. CRRT associated data included vascular access, treatment model, the time of CRRT initiation and total duration of CRRT. Severity of illness was assessed on the basis of number of organ failure and the Simplified Acute Physiology Score II. Baseline value was based on the lowest value before CRRT initiation. For some patients, serum creatinine and urea concentrations at discharge were lower than that before CRRT initiation, and these values were considered to be the basal level. Glomerular filtration rate (GFR) was estimated using the simplified MDRD formula. Modification of the Diet in Renal Disease equation: estimated GFR = 186× (SCr level in mg/dl) $-1.154 \times$ (age in years) -0.203 . The product of this formula is multiplied by a correction factor of 0.742 for women. MPV was calculated by automated blood analyzers. MPR was calculated as the ratio of MPV to platelet count. The initial treatment value was based on the CRRT initial treatment.

\section{Statistical analyses}

Quantitative parameters were reported as mean \pm standard or median and interquartile range (25th, 75th percentile), and qualitative parameters were expressed as number and percentage. Continuous variables were compared using the independent two-sample $t$ test or Mann-Whitney U-test. Categorical 


\section{Kidney \\ Blood Pressure Research}

Kidney Blood Press Res 2018;43:479-489

\begin{tabular}{l|l}
\hline DOI: $10.1159 / 000488694$ & (C) 2018 The Author(s). Published by S. Karger AG, Basel
\end{tabular}

Published onlıne: April 6, 2018 www.karger.com $/ \mathrm{kb}$

variables were compared using the Chi-square test or the Fisher's exact test. The predictive ability of MPR and APACHE II score were assessed with the area under the ROC curve method. Optimal cut-off value was determined by Youden's index. Multiple linear regression analysis was carried out to assess independent relationships between MPR and other variables. Univariate logistic regression analysis was performed to evaluate risk factors associated with the prognosis of AKI. All variables with $\mathrm{P}<0.05$ in univariate analysis were entered into a multivariate analysis. A Hosmer-Lemeshow test was performed to verify the goodness of fit. All tests were two-sides and $\mathrm{P}<0.05$ was considered statistically significant. Statistical analysis was conducted using SPSS 21.0 (SPSS Inc., Chicago, IL).

\section{Results}

\section{Baseline characteristics}

During the 6-year study period, a total of 708 patients who underwent CRRT in our hospital were screened (Fig. 1). Of these, 292 patients were identified as AKI. Of the 292 patients with AKI, 1 was excluded due to aged less than 14 years, 12 were excluded due to length of hospital stay $<48 \mathrm{~h}$. Another 56 were excluded due to inability to obtain complete record. Thus, 223 patients were finally enrolled. Of these, males and the elderly were more common. Hypertension and diabetes accounted for $41.3 \%$ and $25.6 \%$, respectively. ACRS was the most common cause of AKI (15.7\%), followed by sepsis (15.2\%) and trauma (13.9\%). The median hospital stay was 21 days. Of 223 AKI patients, 115 of whom were survivors and 108 of whom were non-survivors. The overall in-hospital mortality was $48.4 \%$, and the mortality of patients with ACRS was higher (51.4\%). There were significant difference between the two groups in age, renal function, hospital stay $(\mathrm{P}<0.05)$. However, no significant differences were observed in other variables $(\mathrm{P}>0.05)$. Demographics and baseline characteristics of these patients are summarized in Table 1.

\section{Clinical characteristics at the CRRT initial treatment}

The comparison between survivors and non-survivors are given in Table 2. Number of organ failure, APACHE II score, WBC, MPV, MPR, serum ALT, serum total bilirubin, serum urea and serum potassium in the non-survivors were significantly higher than those in the survivors $(\mathrm{P}<0.05)$. However, the urine output, arterial $\mathrm{PH}$, platelet count and mean arterial pressure were significantly lower in the non-survivors $(\mathrm{P}<0.05)$. There were no significant differences in other variables between the two groups $(\mathrm{P}>0.05)$. The comparison between between MPR $\leq 0.099$ and MPR $>0.099$ group are summarized in Table S1. For all supplemental material see www.karger.com/doi/10.1159/000488694. Similarly, there were significant difference between the two groups in number of organ failure, APACHE II score, MAP, RDW, MPV, serum albumin, serum ALT, serum total bilirubin and serum urea $(\mathrm{P}<0.05)$.

\section{Comparison of treatments} between survivors and nonsurvivors

The variables that differed significantly between survivors and non-survivors were the percentage of mechanical ventilation use, vasopressor administration and femoral venous access $(\mathrm{P}<0.05)$.

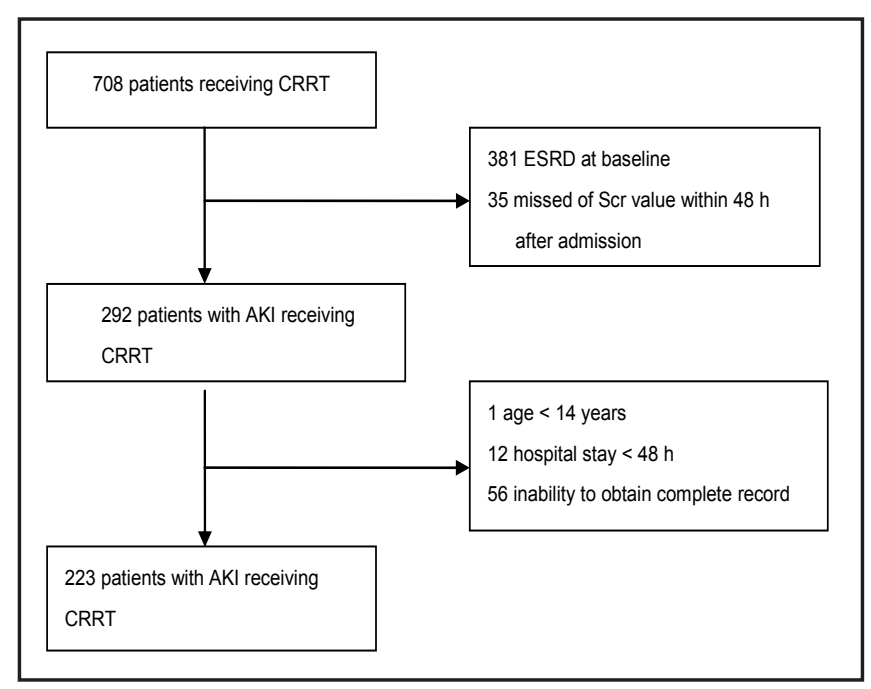

Fig. 1. Study profile. 


\section{Kidney Blood Pressure Research}

Table 1. Baseline characteristics of patients with acute kidney injury. Data are mean \pm standard or medians (first quartile, third quartile) or number (percentage). AKI, acute kidney injury; ACRS, acute cardiorenal syndrome; ICU, intensive care unit; WBC, white blood cell; HB hemoglobin; MPV, mean platelet volume; MPR, Mean Platelet Volume/Platelet Count Ratio; eGFR, estimated glomerular filtration rate

\begin{tabular}{|c|c|c|c|c|}
\hline Characteristics & $\begin{array}{c}\text { Total } \\
(n=223)\end{array}$ & $\begin{array}{c}\text { Survivors } \\
(\mathrm{n}=115)\end{array}$ & Non-survivors $(n=108)$ & $\begin{array}{c}\mathrm{P} \\
\text { value }\end{array}$ \\
\hline Age (yr), mean (S.D.) & $61.4 \pm 19.9$ & $57.4 \pm 19.4$ & $65.6 \pm 19.8$ & 0.002 \\
\hline Sex $(\%$ male $)$ & $147(65.9)$ & $76(66.1)$ & $71(65.7)$ & 0.957 \\
\hline Hypertension (\%) & $92(41.3)$ & $49(42.6)$ & $43(39.8)$ & 0.672 \\
\hline Diabetes mellitus (\%) & $57(25.6)$ & $26(22.6)$ & $31(28.7)$ & 0.297 \\
\hline Admitted to ICU (\%) & $132(59.2)$ & $53(46.1)$ & $79(73.1)$ & 0.006 \\
\hline \multicolumn{5}{|l|}{ First three admission diagnosis } \\
\hline Coronary heart disease (\%) & $32(14.3)$ & $21(18.3)$ & $11(10.2)$ & 0.086 \\
\hline Trauma $(\%)$ & $31(13.9)$ & $15(13.0)$ & $16(14.8)$ & 0.702 \\
\hline AKI (\%) & $17(7.6)$ & $11(9.6)$ & $6(5.6)$ & 0.259 \\
\hline \multicolumn{5}{|l|}{ First three causes of AKI } \\
\hline ACRS $(\%)$ & $35(15.7)$ & $17(14.8)$ & $18(16.7)$ & 0.699 \\
\hline Sepsis (\%) & $34(15.2)$ & $14(12.2)$ & $20(18.5)$ & 0.188 \\
\hline Trauma (\%) & $31(13.9)$ & $15(13.0)$ & $16(14.8)$ & 0.702 \\
\hline \multicolumn{5}{|l|}{ Laboratory examination } \\
\hline WBC $\left(\times 10^{9} / \mathrm{L}\right)$ & $9.6(6.3,13.9)$ & $9.0(6.1,13.2)$ & $10.2(6.3,14.6)$ & 0.401 \\
\hline $\mathrm{HB}(\mathrm{g} / \mathrm{L})$ & $108.5 \pm 30.8$ & $106.7 \pm 32.7$ & $110.4 \pm 28.6$ & 0.373 \\
\hline Platelet count $\left(10^{9} / \mathrm{L}\right)$ & $146(102,210)$ & $174.4 \pm 107.4$ & $157.2 \pm 77.3$ & 0.173 \\
\hline MPV (fl) & $11.1 \pm 1.6$ & $11.0 \pm 1.4$ & $11.2 \pm 1.7$ & 0.428 \\
\hline MPR & $0.076(0.050,0.114)$ & $\begin{array}{c}0.072(0.046 \\
0.116)\end{array}$ & $\begin{array}{c}0.080(0.052 \\
0.110)\end{array}$ & 0.410 \\
\hline Serum albumin (g/L) & $31.6 \pm 9.3$ & $31.3 \pm 9.2$ & $32.0 \pm 9.4$ & 0.543 \\
\hline Serum ALT (U/L) & $31(17,67)$ & $27(15,56)$ & $36(18,78)$ & 0.107 \\
\hline $\begin{array}{l}\text { Serum total bilirubin } \\
(\mu \mathrm{mol} / \mathrm{L})\end{array}$ & $13.4(7 \cdot 6,24)$ & $12(7,21.9)$ & $14(8.2,26)$ & 0.098 \\
\hline Serum creatinine $(\mu \mathrm{mol} / \mathrm{L})$ & $203.0(104.0,403.0)$ & $256(119,528)$ & $151(92.3,327.5)$ & 0.000 \\
\hline Serum urea $(\mathrm{mmol} / \mathrm{L})$ & $13.9(7.9,22.5)$ & $16.7(9.8,29.3)$ & $13.1(6.9,20.2)$ & 0.009 \\
\hline $\mathrm{eGFR}\left(\mathrm{ml} . \mathrm{min} / 1.73 \mathrm{~m}^{2}\right)$ & $24.1(11.2,54.3)$ & $19.0(8.8,49.6)$ & $33.2(16.4,59.9)$ & 0.001 \\
\hline Hospital stay (days) & $21(12,33)$ & $25(16,37)$ & $18(7.3,29.8)$ & 0.000 \\
\hline ICU stay (days) & $5(0,20)$ & $2(0,22)$ & $7(0,18)$ & 0.321 \\
\hline
\end{tabular}

Table 2. Clinical characteristics at the CRRT initial treatment between two groups. Data are mean \pm standard or medians (first quartile, third quartile) or number (percentage). MPV, mean platelet volume; MPR, Mean Platelet Volume/Platelet Count Ratio; CRRT, continuous renal replacement therapy; APACHE II, acute physiologic and chronic health evaluation II; MAP, mean arterial pressure; WBC, white blood cell; HB, hemoglobin; HCT, hematocrit; RDW, red cell volume distribution width; EF, ejection fraction; ProBNP, pro brain natriuretic peptide; CRP, C-reactive protein; Pa02, arterial oxygen partial pressure

\begin{tabular}{|c|c|c|c|c|}
\hline Characteristics & $\begin{array}{c}\text { Total } \\
(n=223)\end{array}$ & $\begin{array}{c}\text { Survivors } \\
(n=115)\end{array}$ & $\begin{array}{c}\text { Non-survivors } \\
(n=108)\end{array}$ & $\begin{array}{c}\mathrm{p} \\
\text { value }\end{array}$ \\
\hline Use of contrast agent (\%) & $66(29.6)$ & $32(27.8)$ & $34(31.5)$ & 0.550 \\
\hline Urine output (ml/d) & $500(150,1000)$ & $500(200,1150)$ & $400(110,868)$ & 0.030 \\
\hline Number of organ failure (n) & $3.0 \pm 1.2$ & $2.4 \pm 1.0$ & $3.7 \pm 0.9$ & 0.000 \\
\hline APACHE II score & $22.0 \pm 5.2$ & $19.3 \pm 3.8$ & $24.9 \pm 4.9$ & 0.000 \\
\hline MAP (mmHg) & $88.1 \pm 17.2$ & $92.5 \pm 15.7$ & $83.4 \pm 17.5$ & 0.000 \\
\hline Arterial PH & $7.35 \pm 0.09$ & $7.36 \pm 0.07$ & $7.33 \pm 0.10$ & 0.010 \\
\hline $\mathrm{PaO} 2(\mathrm{mmHg})$ & $90.9(69.1,95.0)$ & $91.0(67.9,97.0)$ & $90.5(71.1,96.0)$ & 0.076 \\
\hline $\mathrm{HCO}^{-}$ & $19.7 \pm 6.7$ & $20.2 \pm 7.6$ & $19.1 \pm 5.5$ & 0.193 \\
\hline $\mathrm{WBC}\left(\times 10^{12} / \mathrm{L}\right)$ & $13.4 \pm 7.0$ & $12.3 \pm 7.6$ & $14.6 \pm 6.2$ & 0.015 \\
\hline $\mathrm{HB}(\mathrm{g} / \mathrm{L})$ & $98.5 \pm 26.9$ & $99.4 \pm 26.5$ & $97.6 \pm 27.4$ & 0.634 \\
\hline Platelet count $\left(\times 10^{9} / \mathrm{L}\right)$ & $117(89,191)$ & $127(94,221)$ & $104(81,139)$ & 0.001 \\
\hline HCT $(\%)$ & $29.1 \pm 7.8$ & $29.3 \pm 7.4$ & $28.9 \pm 8.2$ & 0.669 \\
\hline RDW (\%) & $15.0 \pm 2.8$ & $15.1 \pm 3.1$ & $14.9 \pm 2.6$ & 0.663 \\
\hline $\operatorname{MPV}(\mathrm{fl})$ & $11.4 \pm 1.8$ & $11.1 \pm 1.9$ & $11.7 \pm 1.7$ & 0.011 \\
\hline MPR & $\begin{array}{c}0.097(0.055 \\
0.138)\end{array}$ & $\begin{array}{c}0.082(0.048 \\
0.123)\end{array}$ & $\begin{array}{c}0.110(0.076 \\
0.160)\end{array}$ & 0.000 \\
\hline Serum albumin $(\mathrm{g} / \mathrm{L})$ & $29.3 \pm 7.1$ & $29.6 \pm 6.7$ & $29.0 \pm 7.6$ & 0.537 \\
\hline Serum ALT (U/L) & $37(19,161)$ & $32(17,84)$ & $53(24,229)$ & 0.011 \\
\hline Serum total bilirubin $(\mu \mathrm{mol} / \mathrm{L})$ & $15.0(9.1,33.0)$ & $13.0(6.9,29.0)$ & $18.0(11.0,42.8)$ & 0.005 \\
\hline Serum creatinine $(\mu \mathrm{mo} / \mathrm{L})$ & $462.4 \pm 238.1$ & $484.7 \pm 255.6$ & $438.6 \pm 216.5$ & 0.147 \\
\hline Serum urea $(\mathrm{mmol} / \mathrm{L})$ & $29.3 \pm 14.0$ & $26.7 \pm 12.8$ & $32.0 \pm 14.7$ & 0.005 \\
\hline Serum potassium (mmol/L) & $4.6 \pm 1.0$ & $4.4 \pm 0.9$ & $4.8 \pm 1.1$ & 0.010 \\
\hline $\mathrm{EF}(\%)$ & $55.0 \pm 10.1$ & $56.7 \pm 9.4$ & $52.8 \pm 10.8$ & 0.079 \\
\hline ProBNP (ng/L) & $14587(8059,14587)$ & $\begin{array}{c}14587(8059 \\
14587)\end{array}$ & $14587(8041,14587)$ & 0.173 \\
\hline $\mathrm{CRP}(\mathrm{mg} / \mathrm{L})$ & $46.7(9.2,121.3)$ & $38.1(8.6,119.0)$ & $78.6(13.1,138.3)$ & 0.372 \\
\hline Stage AKI (stage 2/ stage 3) & $15 / 208$ & $10 / 105$ & $5 / 103$ & 0.226 \\
\hline
\end{tabular}




\section{Kidney \\ Blood Pressure Research}

Table 3. Comparison of treatments between survivors and non-survivors. Data are medians (first quartile, third quartile) or number (percentage). CRRT, continuous renal replacement therapy; CVVH, continuous veno-venous hemofiltration

\begin{tabular}{lcccc}
\hline Characteristics & $\begin{array}{c}\text { Total } \\
(\mathrm{n}=223)\end{array}$ & $\begin{array}{c}\text { Survivors } \\
(\mathrm{n}=115)\end{array}$ & Non-survivors (n=108) & $\begin{array}{c}\mathrm{p} \\
\text { value }\end{array}$ \\
\hline Mechanical ventilation use (\%) & $137(61.4)$ & $41(35.7)$ & $96(88.9)$ & 0.000 \\
Vasopressor administration (\%) & $143(64.1)$ & $37(32.2)$ & $106(98.1)$ & 0.000 \\
Diuretics administration (\%) & $215(96.4)$ & $109(94.8)$ & $106(98.1)$ & 0.177 \\
CRRT mode (\%CVVH) & $178(79.8)$ & $91(79.1)$ & $87(80.6)$ & 0.791 \\
Vascular access (\%Femoral vein) & $189(84.8)$ & $88(76.5)$ & $101(93.5)$ & 0.000 \\
Duration of CRRT (hours) & $16(10,35)$ & $16(10,30)$ & $15(8,35)$ & 0.203 \\
\hline
\end{tabular}

No significant differences were found in the diuretics administration, CRRT model and duration of CRRT (P > $0.05)$. The comparison of some treatments between survivors and non-survivors are shown in Table 3.

At post-CRRT treatment, there were significant differences in WBC, platelet count, and MPR between survivors and non-survivors. No significant differences were observed in other routine blood variables (Table S2).

\section{Analysis of related factors}

of MPR at the CRRT initial

treatment in patients

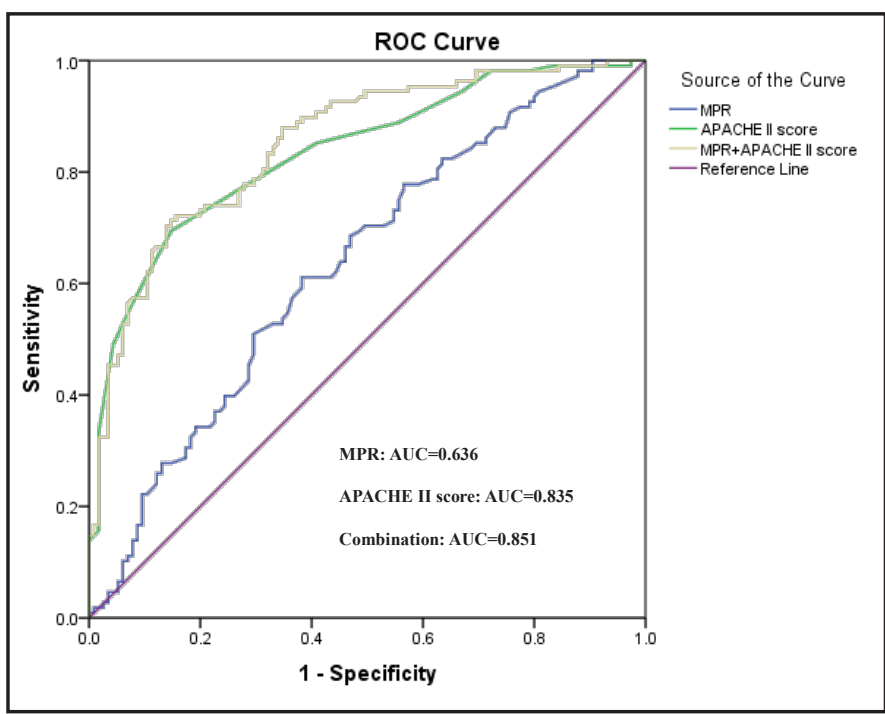

Fig. 2. ROC curves of MPR, APACHE II score and the combination of them for predicting mortality in patients with AKI.

To assess independent

relationships between MPR at the CRRT initial treatment and other variables, a multiple linear regression analysis was carried out. The results revealed that platelet count and MPV at the CRRT initial treatment had significant linear relationships with MPR $(P<0.05)$. However, other factors such as age, number of organ failure, liver function and APACHE II score had no significant relationship with MPR. The regression equation was: MPR $=0.372$ $-0.001 \times$ platelet count $+0.009 \times$ MPV .

\section{MPR for predicting in-hospital mortality in AKI patients}

ROC analysis of MPR for predicting in-hospital mortality in AKI patients was performed. The area under the ROC curve of MPR was 0.636 (95\% CI, 0.563-0.708; P < 0.001). The optimal cut-off value of MPR was 0.099 . The sensitivity, specificity and accuracy were $55.7 \%$, $61.1 \%$ and $58.3 \%$, respectively. The in-hospital mortality of patients whose MPR $>0.099$ was $56.4 \%$ (66/117), which was higher than those MPR $\leq 0.099$ (39.6\%, 42/106), and the difference was statistically significant (Chi square $=6.276, \mathrm{P}=0.012$ ). To assess whether a combination of MPR with APACHE II score could improve the prediction value of in-hospital mortality, ROC analysis was performed. The results showed that the AUC was 0.835 (95\% CI, $0.782-0.888$; $\mathrm{P}<0.001)$ when the score was used alone, whereas it increased to $0.851(95 \%$ CI, 0.802-0.901; $\mathrm{P}<0.001$ ) with the addition of MPR to the score. The ROC curves are shown in Fig. 2. 


\section{Kidney Blood Pressure Research}

Li et al.: Mean Platelet Volume/Platelet Count Ratio and Acute Kidney Injury

Table 4. Risk factors associated with prognosis in the multivariable

Risk factors for prognosis in AKI patients

Multivariate logistic regression analysis of risk factors was performed. In order to exclude the multiple collinearity effects of variables in the regression model, stepwise regression method was used. The results demonstrated that vasopressor administration, number of organ failure age, and APACHE II score were independent risk factors for adverse outcome in patients with AKI (Table 4). The regression equation was $\mathrm{y}=12.322+3.641 \times$ vasopressor administration $+0.864 \times$ number of organ failure $+0.172 \times$ APACHE II score +0.028 age. The Hosmer-Lemeshow test indicated that the goodness of fit was satisfactory (Chi square $=4.501, \mathrm{P}=0.741$ ).

\section{Discussion}

In the present study, we compared the clinical characteristics of patients with AKI who received CRRT between survivals group and non-survivals group, and investigated the predictive value of MPR combined with APACHE II score for in-hospital mortality of these patients, using retrospective data from 223 patients between 2009 and 2014 in our hospital. The results indicated that the severity of illness was significantly associated with prognosis of patients with AKI. Furthermore, this study revealed that a combination of MPR and APACHE II score performed better in predicting short-term mortality in patients with AKI.

Despite all advances in knowledge regarding the pathogenesis and treatment of AKI, it is still a relatively common complication in critically ill patients and is associated with mortality independently of other risk factors [24-25]. Because the etiology of AKI varies widely, the prognosis is not the same [26]. Our previous study showed that the overall mortality rate of AKI patients in the hospital was 31.9\% [6]. In this study, the all-cause mortality of patients was $48.4 \%$, which was higher in the patients with ACRS (51.4\%). Furthermore, ACRS was the most common cause of AKI in the present study. ACRS is characterized as the development of AKI in the patient with acute cardiac illness [27-29]. Previous studies have shown that the incidence of AKI in acute decompensated heart failure and acute coronary syndromes was $20-45 \%$ and $9-20 \%$, respectively, while in cardiogenic shock, up to $70 \%$ of patients might develop AKI [30-32]. In addition, our study showed that sepsis and trauma were also common causes of severe AKI. Sepsis accounts for $26 \%$ to $50 \%$ of the etiology of AKI in developed countries [33]. It's worth noting that trauma has become a new and important cause in community-acquired AKI in developing countries, especially brain injury due to traffic accidents [34]. Similarly, our study showed that trauma was the third leading cause of AKI. Therefore, trauma should be regarded as an important preventable cause of AKI.

Several studies have suggested platelet activation exacerbates renal injury [10-11]. Our previous study [35] also showed that in rat renal ischemia-reperfusion injury, P-selectin was widely expressed in renal tissue, especially in renal tubular epithelial cells. Furthermore, inhibition of P-selectin could ameliorate cell necrosis and inflammation. In the present study, we compared clinical characteristics between survivors and non-survivors and found that MPV value at the CRRT initial treatment was higher in non-survivals group, however, the value of platelet count was just the opposite. It is reported that thrombocytopenia is common in critically ill patients, and is associated with an increase in incidence of AKI as well prolonged ICU stay [18]. MPV is a universally available parameter with routine blood test. Elevated 


\section{Kidney Blood Pressure Research}

Kidney Blood Press Res 2018;43:479-489

\begin{tabular}{l|l}
\hline DOI: $10.1159 / 000488694$ & (C) 2018 The Author(s). Published by S. Karger AG, Basel
\end{tabular}

Published onlıne: April 6, 2018

www.karger.com $/ \mathrm{kb}$

MPV is an indicator of larger, more reactive platelets resulting from an increased platelet turnover. Recent studies revealed that MPV levels were positively correlated with platelet activation, and high MPV represented a risk factor for overall cardiovascular mortality [3637]. In addition, the high MPV was also related to poor prognosis in non-cardiovascular disease critically ill patients [38]. A retrospective study including 349 patients with AKI who underwent CRRT showed that MPV levels were in a positive correlation with the APACHE II score, and MPV was an independent predictor of mortality [39]. However, recent studies suggested combination of platelet count and mean platelet volume may be more clinically significant than platelet count or MPV alone [20-22]]. Consistently, our study showed an inverse relationship between MPV and platelet counts. Furthermore, we found that the patients in MPR $>0.099$ group were more serious condition, and MPR had predictive value for in-hospital mortality in patients with AKI. The optimal cut-off value of MPR for mortality was 0.099 with AUC of 0.636 . The AUC increased to 0.851 with the addition of the APACHE II score. The mortality of patients with of MPR $>0.099$ was $56.4 \%$, which was significantly higher than that of the control group with of $\leq 0.099(39.6 \%, P=0.012)$. Also, there was a significant difference in MPR at post-CRRT treatment between the two groups. Platelet count and MPV are two main characteristics to evaluate platelet activation [40]. Our findings demonstrated MPR may be a reliable predictive prognostic marker for severe patients with AKI. Although the AUC of MPR was relatively low, the combination of MPR and APACHE II score could increase the predictive ability. Thus, we suggest MPV should be performed on all patients with AKI , MPR should be calculated and combined with APACHE II score to assess the prognosis of AKI.

In this study, multiple logistic regression analysis indicated that average number of organ failure, APACHE II score, age and vasopressors administration were independent risk factors of AKI. A recent multi-center study [41] evaluated risk factors of AKI in China, they found independent risk factors for AKI were advancing age, male gender, hypertension, and CKD. In addition, the predictors of mortality in patients with AKI were advancing age, tumor, higher uric acid level and increases in APACHE II and Sequential Organ Failure Assessment (SOFA) scores. Similarly, our study results suggest the severity of illness and extrarenal organ failure are still important risk factors for death of patients with severe AKI. Therefore, the prevention and treatment of extrarenal complications is the key to prevent and slow down the progression of AKI.

Our study had several limitations. First, due to the retrospective observational design with its inherent biases, the control of confounding factors may be insufficient, although data were collected from medical records with a presumed high level of accuracy. It's well known that there were many factors affecting MPV, such as antiplatelet agents, smoking, hematologic diseases, malignancy, inflammation, or any recent transfusions [23]. However, it was difficult to obtain all the factors. These could have an impact on our results. Second, some patients did not have pre-admission blood routine and blood biochemical indices. Although we made an effort to obtain them, a few data still could not be provided. In fact, this was common in clinical practice [36], especially in developing countries. This may result in less accurate baseline data. Third, MPV levels were followed up for a short time, rather than continuously monitored, which made the significance of the study limited. Lastly, this was a single-center observational study, not a large, multi-center study. Thence, the generalizability of the study results might be limited.

\section{Conclusion}

We analyze the etiology, prognosis and risk factors of severe AKI patients treated with CRRT for 6 years in our whole hospital, and further explore the role of MPR in them. The results show that the combination of MPR and APACHE II score may be helpful in predicting 


\section{Kidney \\ Blood Pressure Research}

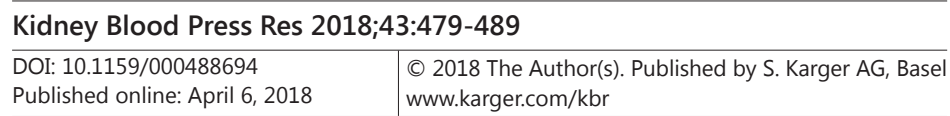

Li et al.: Mean Platelet Volume/Platelet Count Ratio and Acute Kidney Injury

the short-term outcome of AKI. Besides, the severity of illness is closely related to the prognosis of AKI.

\section{Acknowledgements}

We thank the staff of the Medical Records Room and Biochemical Room for their assistance. We thank Xiaoqing Pan (Department of Bioinformatics, Medical College of Wisconsin) for her help in statistical analysis. We thank Michelle Robert (Department of Physiology, Medical College of Wisconsin) for her help in English editing. We thank our patients and their families for their participation. This study was supported by a grant from the National Natural Science Foundation of China (No.81270824). The funder had no role in the design of the study, data collection and statistical analysis, decision to publish, or preparation of the manuscript.

\section{Disclosure Statement}

The authors declare that they have no competing interests.

\section{References}

$\rightarrow 1$ Siew ED, Davenport A: The growth of acute kidney injury: a rising tide or just closer attention to detail? Kidney Int 2015;87:46-61.

-2 Clemens MS, Stewart IJ, Sosnov JA, Howard JT, Belenkiy SM, Sine CR, Henderson JL, Buel AR, Batchinsky AI, Cancio LC, Chung KK: Reciprocal Risk of Acute Kidney Injury and Acute Respiratory Distress Syndrome in Critically Ill Burn Patients. Crit Care Med 2016;44:e915-922.

- Y Yang L, Xing G, Wang L, Wu Y, Li S, Xu G, He Q Chen J, Chen M, Liu X, Zhu Z, Yang L, Lian X, Ding F, Li Y, Wang H, Wang J, Wang R, Mei C, Xu J, et al.: ISN AKF 0by25 China Consortiums: Acute kidney injury in China: a cross-sectional survey. Lancet 2015;386:1465-1471.

-4 Fang Y, Ding X, Zhong Y, Zou J, Teng J, Tang Y, Lin J, Lin P: Acute kidney injury in a Chinese hospitalized population. Blood Purif 2010;30:120-126.

5 Wald R, Shariff SZ, Adhikari NK, Bagshaw SM, Burns KE, Friedrich JO, Garg AX, Harel Z, Kitchlu A, Ray JG: The association between renal replacement therapy modality and long-term outcomes among critically ill adults with acute kidney injury: a retrospective cohort study. Crit Care Med 2014;42:868-877.

6 Li JH, Wang NS, Wang F, Xiang HY, Wu HL, Wu QM: Acute renal failure in hospitalized patients in China: a prospective study. Ren Fail 2009;31:431-437.

7 Chang CH, Fan PC, Chang MY, Tian YC, Hung CC, Fang JT, Yang CW, Chen YC: Acute Kidney Injury Enhances Outcome Prediction Ability of Sequential Organ Failure Assessment Score in Critically Ill Patients. PLoS One 2014;9:e109649.

-8 Chawla LS, Eggers PW, Star RA, Kimmel PL: Acute kidney injury and chronic kidney disease as interconnected syndromes. N Engl J Med 2014;371:58-66.

9 Bell M, Chawla LS, Wald R: Understanding renal recovery. Intensive Care Med 2017;43:924-926.

$>10$ Schwarzenberger C, Sradnick J, Lerea KM, Goligorsky MS, Nieswandt B, Hugo CP, Hohenstein B: Platelets are relevant mediators of renal injury induced by primary endothelial lesions. Am J Physiol Renal Physiol 2015;308:1238-1246.

11 Jansen MP, Emal D, Teske GJ, Dessing MC, Florquin S, Roelofs JJ: Release of extracellular DNA influences renal ischemia reperfusion injury by platelet activation and formation of neutrophil extracellular traps. Kidney Int 2017;91:352-364.

12 Massaguer A, Engel P, Pérez-del-Pulgar S, Bosch J, Pizcueta P: Production and characterization of monoclonal antibodies against conserved epitopes of P-selectin (CD62P). Tissue Antigens 2000;56:117128. 


\section{Kidney \\ Blood Pressure Research}

Li et al.: Mean Platelet Volume/Platelet Count Ratio and Acute Kidney Injury

13 Michelson AD, Barnard MR, Krueger LA, Valeri CR, Furman MI: Circulating monocyte-platelet aggregates are a more sensitive marker of in vivo platelet activation than platelet surface P-selectin: studies in baboons, human coronary intervention, and human acute myocardial infarction. Circulation 2001;104:1533-1537.

14 Chertow GM, Soroko SH, Paganini EP, Cho KC, Himmelfarb J, Ikizler TA, Mehta RL: Mortality after acute renal failure: models for prognostic stratification and risk adjustment. Kidney Int 2006;70:1120-1126.

15 Luo X, Jiang L, Du B, Wen Y, Wang M, Xi X, Beijing Acute Kidney Injury Trial (BAKIT) workgroup: A comparison of different diagnostic criteria of acute kidney injury in critically ill patients. Crit Care 2014;18:R144.

-16 Vanderschueren S, De Weerdt A, Malbrain M, Vankersschaever D, Frans E, Wilmer A, Bobbaers H: Thrombocytopenia and prognosis in intensive care. Crit Care Med 2000;28:1871-1876.

17 Zampieri FG, Ranzani OT, Sabatoski V, de Souza HP, Barbeiro H, da Neto LM, Park M, Pinheiro da Silva F: An increase in mean platelet volume after admission is associated with higher mortality in critically ill patients. Ann Intensive Care 2014;4:20.

18 Venkata C, Kashyap R, Farmer JC, Afessa B: Thrombocytopenia in adult patients with sepsis: incidence, risk factors, and its association with clinical outcome. J Intensive Care 2013;1:9-14.

19 Tajarernmuang P, Phrommintikul A, Limsukon A, Pothirat C, Chittawatanarat K: The Role of Mean Platelet Volume as a Predictor of Mortality in Critically Ill Patients: A Systematic Review and Meta-Analysis. Crit Care Res Pract 2016:4370834.

20 Shin DH, Rhee SY, Jeon HJ, Park JY, Kang SW, Oh J: An Increase in Mean Platelet Volume/Platelet Count Ratio Is Associated with Vascular Access Failure in Hemodialysis Patients. PLoS One 2017;12:e0170357.

-21 Zhang F, Chen Z, Wang P, Hu X, Gao Y, He J: Combination of platelet count and mean platelet volume (COPMPV) predicts postoperative prognosis in both resectable early and advanced stage esophageal squamous cell cancer patients. Tumour Biol 2016;37:9323-9331.

22 Gao L, Zhang H, Zhang B, Zhang L, Wang C: Prognostic value of combination of preoperative platelet count and mean platelet volume in patients with resectable non-small cell lung cancer. Oncotarget 2017;8:1563215641.

23 Goldberg RJ, Spencer FA, Gore JM, Lessard D, Yarzebski J: Thirty-year trends (1975 to 2005) in the magnitude of, management of, and hospital death rates associated with cardiogenic shock in patients with acute myocardial infarction: a population-based perspective. Circulation 2009;119:1211-1219.

24 Bellomo R, Ronco C, Kellum JA, Mehta RL, Palevsky P: Acute Dialysis Quality Initiative workgroup Acute renal failure - definition, outcome measures, animal models, fluid therapy and information technology needs: the Second International Consensus Conference of the Acute Dialysis Quality Initiative (ADQI) Group. Crit Care 2004;8:R204-R212.

-25 Doyle JF, Forni LG: Acute kidney injury: short-term and long-term effects. Crit Care 2016;20:188.

26 Poukkanen M, Vaara ST, Reinikainen M, Selander T, Nisula S, Karlsson S, Parviainen I, Koskenkari J, Pettilä V, FINNAKI Study Group: Predicting one-year mortality of critically ill patients with early acute kidney injury: data from the prospective multicenter FINNAKI study. Crit Care 2015;19:125-130.

27 Ronco C, McCullough P, Anker SD, Anand I, Aspromonte N, Bagshaw SM, Bellomo R, Berl T, Bobek I, Cruz DN, Daliento L, Davenport A, Haapio M, Hillege H, House AA, Katz N, Maisel A, Mankad S, Zanco P, Mebazaa A, et al.: Cardio-renal syndromes: report from the consensus conference of the acute dialysis quality initiative. Eur Heart J 2010;31:703-711.

-28 Eren Z, Ozveren O, Buvukoner E, Kaspar E, Degertekin M, Kantarci G: A Single-Centre Study of Acute Cardiorenal Syndrome: Incidence, Risk Factors and Consequences. Cardiorenal Med 2012;2:168-176.

29 Ronco C, Cicoira M, McCullough P: Cardiorenal syndrome type 1: pathophysiological crosstalk leading to combined heart and kidney dysfunction in the setting of acutely decompensated heart failure. J Am Coll Cardiol 2012;60:1031-1042.

30 Virzì GM, Day S, de Cal M, Ronco C: Heart-kidney crosstalk and role of humoral signaling in critical illness. Crit Care 2014;18:201.

31 Bagshaw SM, Cruz DN, Aspromonte N, Daliento L, Ronco F, Sheinfeld G: Acute Dialysis Quality Initiative Consensus Group. Epidemiology of cardio-renal syndromes: workgroup statements from the 7th ADQI consensus conference. Nephrol Dial Transpl 2010;25:1406-1416. 


\section{Kidney \\ Blood Pressure Research}

Li et al.: Mean Platelet Volume/Platelet Count Ratio and Acute Kidney Injury

-32 Fonarow GC, Stough WG, Abraham WT, Albert NM, Gheorghiade M, Greenberg BH: Characteristics, treatments, and outcomes of patients with preserved systolic function hospitalized for heart failure: a report from the OPTIMIZE-HF registry. J Am Coll Cardiol 2007;50:768-777.

-33 Alobaidi R, Basu RK, Goldstein SL, Bagshaw SM: Sepsis-Associated Acute Kidney Injury. Semin Nephrol 2015;35:2-11.

-34 Santos PR, Monteiro DLS: Acute kidney injury in an intensive care unit of a general hospital with emergency room specializing in trauma: an observational prospective study. BMC Nephrol 2015;16:30-35.

35 Li JH, Wang F, Wang NS, Jian GH, Xue Q: Effects of Magnolin on Expression of P-selectin in Rats with Renal Ischemic Reperfusion Injury. Chin J Integr Tradit Western Nephrol 2008;9:586-588.

36 Slavka G, Perkmann T, Haslacher H, Greisenegger S, Marsik C, Wagner OF, Endler G: Mean platelet volume may represent a predictive parameter for overall vascular mortality and ischemic heart disease. Arterioscler Thromb Vasc Biol 2011;31:1215-1218.

37 Citirik M, Beyazyildiz E, Simsek M, Beyazyildiz O, Haznedaroglu IC: MPV may reflect subcinical platelet activation in diabetic patients with and without diabetic retinopathy. Eye (Lond) 2015;29:376-379.

38 Kim CH, Kim SJ, Lee MJ, Kwon YE, Kim YL, Park KS, Ryu HJ, Park JT, Han SH, Yoo TH, Kang SW, Oh HJ: An Increase in Mean Platelet Volume from Baseline Is Associated with Mortality in Patients with Severe Sepsis or Septic Shock. PLoS One 2015;10:e0119437.

-39 Han JS, Park KS, Lee MJ, Kim CH, Koo HM, Doh FM, Kim EJ, Han JH, Park JT, Han SH, Yoo TH, Kang SW, Oh HJ: Mean platelet volume is a prognostic factor in patients with acute kidney injury requiring continuous renal replacement therapy. J Crit Care 2014;29:1016-1021.

-40 Kamath S, Blann AD, Lip GY: Platelet activation: assessment and quantification. Eur Heart J 2001;22:15617151.

41 Nie S, Feng Z, Tang L, Wang X, He Y, Fang J, Li S, Yang Y, Mao H, Jiao J, Liu W, Cao N, Wang W, Sun J, Shao F, Li W, He Q, Jiang H, Lin H, Fu P, et al.: Risk Factor Analysis for AKI Including Laboratory Indicators: a Nationwide Multicenter Study of Hospitalized Patients. Kidney Blood Press Res 2017;42:761-773. 